\title{
Correction to: Algorithm for the Estimation of Continental Scale Land- Surface Broadband Albedo from INSAT-3D Imager Data
}

\author{
Mehul R. Pandya ${ }^{1} \cdot$ Vishal Pathak ${ }^{2} \cdot$ Nitesh Kaushik $^{1} \cdot$ Himanshu J. Trivedi ${ }^{2}$
}

(C) Indian Society of Remote Sensing 2021

\section{Correction to: Journal of the Indian Society of Remote Sensing} https://doi.org/10.1007/s12524-021-01371-0

Inadvertently, in the mentioned article, typesetters have missed a symbol in the equations (Eqs. 4, 5, 6).

The original online version of this article was revised.

Publisher's Note Springer Nature remains neutral with regard to jurisdictional claims in published maps and institutional affiliations.

The original article can be found online at https:// doi.org/10.1007/s12524-021-01371-0.

Mehul R. Pandya mrpandya@hotmail.com

1 Space Applications Centre, ISRO, Ahmedabad, India

2 NVPAS, CVM, Vallabh Vidyanagar, India 